\title{
Pengaruh Variasi Topologi Elektroda terhadap Kadar Ozon yang dihasilkan oleh Generator Ozon
}

\author{
Yugo Triawanto* dan Endarko \\ Jurusan Fisika, Fakultas Matematika dan Ilmu Pengetahuan Alam, \\ Institut Teknologi Sepuluh Nopember (ITS), Kampus ITS Sukolilo, Surabaya 60111
}

Intisari

Generator ozon dengan variasi topologi elektroda telah berhasil dibuat untuk mengetahui pengaruhnya terhadap jumlah kadar ozon yang dihasilkan. Desain generator sehingga menyebabkan terjadi lucutan elektron yang banyak menjadi sebuah pilihan untuk mendapatkan penghasil ozon yang optimal. Desain topologi elektroda yang dipilih dalam penelitian ini adalah elektroda koaksial dan strip bidang. Kedua elektroda ini dibandingkan kemampuan dalam menghasilkan ozon dengan frekuensi 11,9 KHz. Variasi dimensi dilakukan pula pada kedua jenis elektroda, masing-masing terdapat tiga variasi dimensi untuk mengetahui pengaruhnya terhadap kadar ozon yang dihasilkan. Generator ozon elektroda strip bidang menghasilkan ozon terlarut sebesar $2,87 \mathrm{mg}$ sedangkan generator elektroda koaksial 2,17 mg.

\begin{abstract}
Ozone generators with electrodes topological variations have been constructed to determine of the effect on the amount of ozone levels produced. Design led to a discharge electrons which are becoming an option to obtain optimal ozone producer. Topology design of electrodes selected in this study is the coaxial electrodes and strip plane. Both of these electrodes are compared in terms of the ability to produce ozone with frequency $11,9 \mathrm{KHz}$. Dimension variation performed well on both types of electrodes, there are three dimensions for each variations to determine its effect on the levels of ozone generated. Ozone generators with electrode of the strip plane produce ozone dissolved by $2.87 \mathrm{mg}$ while the electrode coaxial $2.17 \mathrm{mg}$.
\end{abstract}

KATA KUNCI: generator ozon, elektroda, koaksial, strip-plane

\section{PENDAHULUAN}

Ilmu pengetahuan dan teknologi saat ini semakin berkembang. Seiring perkembangannya ada beberapa efek yang ditimbulkan, baik efek positif maupun negatif. Salah satu efek negatif yang ditimbulkan adalah polusi yang semakin tinggi, baik polusi udara, air maupun polusi yang lain. Tentu saja polusi ini harus ditekan agar efek negatif dari perkembangan Ilmu pengetahuan dan teknologi bisa diantisipasi. Seharusnya ada pengembangan ilmu pengetahuan dan teknologi yang bisa memberikan kontribusi dalam mengurangi polusi.

Teknologi pengurangan polutan sudah dilakukan dengan beberapa macam penanganan baik dengan cara konvensional seperti wastewater treatment plants atau teknik penanganan yang non-konvensional seperti advanced oxidation processes (AOPs) [1]. Pengembangan teknologi penghilangan polutan dengan dielectric barrier discharges (DBD) masih berlangsung dengan tujuan untuk mendapatkan efisiensi dan kadar ozon yang tinggi. DBD bisa dihasilkan dengan menggunakan arus listrik AC beserta kelengkapan lainnya yakni elektroda dan bahan dielektrik yang diletakkan antara elektroda positif dan elektroda negatif [2].

Tujuan utama dari penelitian ini adalah merancang, membuat dan menganalisa serta menguji generator ozon dari

\footnotetext{
*E-MAIL: yugotriawanto@gmail.com
}

topologi elektroda strip bidang dan koaksial dalam proses produksi ozon yang dihasilkan.

Ozon adalah oksidan yang dapat diaplikasikan pada air dan udara. Beberapa aplikasi untuk pengolahan makanan juga ada yang menggunakan ozon sebagai pengendali reaksi kimia dengan tujuan tertentu. Disinfektan yang ada sekarang juga beberapa berbasis generator ozon [3]. Ozon sangat disenangi masyarakat khususnya terkait dalam penggunaannya untuk mengolah makanan, karena bisa menggantikan fungsi zat aditif pada makanan serta merupakan teknologi yang ramah lingkungan dan tidak berbahaya bagi manusia [4]. Ozon menjadi alternatif bagi industri dalam perannya untuk membersihkan makanan tanpa meninggalkan residu. Pembersihan pada makanan dengan cara pembersihan menggunakan air yang didalamnya terkandung ozon dan penyimpanan makanan yang udaranya mengandung ozon. Ozon dapat berfungsi sebagai pestisida yang mengakibatkan serangga perusak makanan mati tanpa memberikan efek negatif kepada makanan yang dikenai. Rasa dari makanan adalah menjadi hal yang sangat penting bagi konsumen makanan, sehingga ozon sebagai oksidan yang digunakan untuk pengolahan makanan menjadi sangat penting.

Gas rumah kaca sudah ada didalam atmosfir dalam kurun waktu puluhan tahun bahkan ratusan. Hal ini berpengaruh pada keseimbangan energi pada bumi dalam kurun waktu yang cukup lama. Gangguan keseimbangan energi pada bumi terjadi seperti adanya pelepasan energi ke udara sebelum waktunya yang disebabkan perubahan iklim yang tidak 


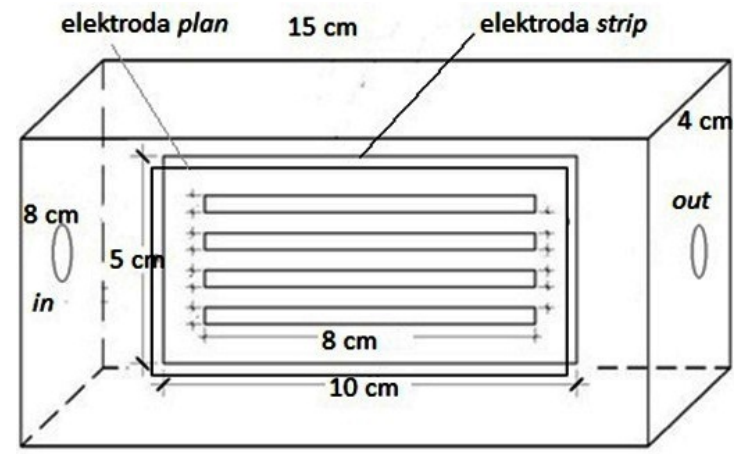

Gambar 1: Reaktor ozon elektroda strip bidang.

periodik akibat gas rumah kaca. Sebagian besar gas rumah kaca adalah karbon dioksida yang diemisikan akibat pemakaian energi fosil. Karbon Dioksida dihasilkan ketika makhluk hidup bernafas mengeluarkan karbon dioksida dan pemakaian kendaraan, power plan [5].

Pada umumnya generator ozon terdiri dari sumber tegangan tinggi, elektroda dan dielektrikum yang berada dalam reaktor ozon. Pada generator ozon yang menggunakan elektroda plat paralel medan listrik yang terjadi tidak homogen. Medan listrik pada bagian tepi lebih lemah jika dibanding dengan medan listrik yang timbul pada bagian tengah elektroda [6]. Dielectric barrier discharge merupakan piranti yang sangat efisien dalam skala industri karena efektif dan ekonomis.

\section{METODE PENELITIAN}

Generator ozon yang dibuat pada penelitian ini menggunakan beberapa bagian salah satunya adalah pembangkit tegangan tinggi. Pembangkit tegangan tinggi menggunakan trafo flyback yang diberi masukan tegangan DC dari power supply kemudian masuk rangkaian timer dengan frekuensi $11,9 \mathrm{KHz}$. Kemudian tegangan luaran dari trafo flyback dihubungkan dengan elektroda koaksial dan strip bidang. Elektroda strip bidang yang digunakan pada penelitian ini beserta reaktornya ditunjukkan pada Gambar 1 .

Jarak antara kedua elektroda strip bidang adalah $1 \mathrm{~cm}$. Kedua elektroda dialiri dengan tegangan tinggi dan udara dipompakan melalui lubang in kemudian udara yang keluar dari lubang out dialirkan pada cairan KI 0,15 M. Perlakuan ini dilakukan dengan variasi durasi waktu 5, 10 dan 15 menit serta variasi jumlah strip elektroda yang dipakai. Demikian pula elektroda koaksial dipakai pada penelitian ini dengan variasi diameter 1, 2 dan $3 \mathrm{~cm}$ seperti pada Gambar 2 .

Prosedur pengujian ozon dengan KI adalah sebagai berikut:

1. Pembuatan larutan KI dengan konsentrasi $0,15 \mathrm{M}$

2. Pembuatan sodium tiosulfat $0,015 \mathrm{~N}$ dengan rumus normalitas

massa molar ekivalen $=\frac{\operatorname{Mr} \text { molekul }(\mathrm{g} / \mathrm{mol})}{\text { ekivalensi }(\mathrm{eq} / \mathrm{mol})}$

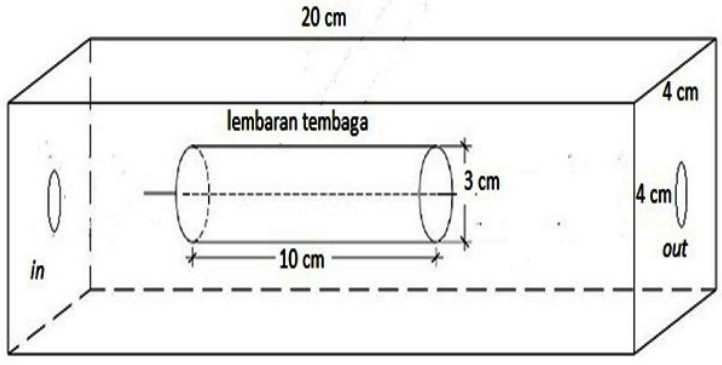

Gambar 2: Reaktor ozon elektroda koaksial.

$$
\text { Normalitas }=\frac{\text { massa } /(\text { massa molar ekivalen })(\mathrm{eq})}{\text { volume }(\text { liter })}
$$

3. Pembuatan larutan indikator starch $1 \%$

4. Pembuatan larutan Asam Sulfat 0,005M

5. Proses iodometri mengalirkan gas dari ozon generator kedalam tabung berisi KI dengan penambahan asam sulfat $0,005 \mathrm{M}$. Pada proses iodometri jumlah ozon yang terperangkap sebanding dengan pembentukan iodine. Reaksi pembentukan iodine adalah sebagai berikut:

$$
\mathrm{O}_{3}+2 \mathrm{I}^{-}+2 \mathrm{H}^{+} \rightarrow \mathrm{O}_{2}+\mathrm{I}_{2}+\mathrm{H}_{2} \mathrm{O}
$$

6. Dilakukan proses titrasi menggunakan sodium tiosulfat $0,015 \mathrm{~N}$ dengan reaksi kimia sebagai berikut:

$$
I_{2}+2 S_{2} O_{3}^{-} \rightarrow 2 I^{-}+S_{4} O_{6}^{-}
$$

Titrasi dihentikan ketika terjadi titik kesetimbangan yaitu saat warna larutan berubah dari biru tua menjadi jernih. Penyamaan massa molekul relatif antara ozon dan sodium tiosulfat memberikan konstanta 24 (g/eq).

7. Penghitungan jumlah kandungan Ozon dengan persamaan:

$$
\begin{aligned}
O_{3}(m g)= & 24\left(\frac{m g}{m e q}\right) \times \operatorname{vol~} \mathrm{Na}_{2} S_{2} \mathrm{O}_{3}(m L) \\
& \times \text { normalitas }\left(\frac{m e q}{m L}\right)
\end{aligned}
$$

\section{HASIL DAN PEMBAHASAN}

Dielektrik diantara kedua elektroda berfungsi untuk membatasi arus lucutan pada generator ozon [6]. Pada Gambar 1 reaktor ozon elektroda strip-bidang tidak menggunakan bahan dielektrikum, hasilnya adalah plasma sukar terbentuk dan timbul spark. Spark muncul hanya pada beberapa bagian saja dari elektroda karena jarak antara dua elektroda tidak seluruhnya homogen meskipun hanya dalam kisaran mm. Spark timbul karena jarak antara dua elektroda terlalu jauh dan daya power supply terlalu besar. Namun jika daya dikecilkan, maka 


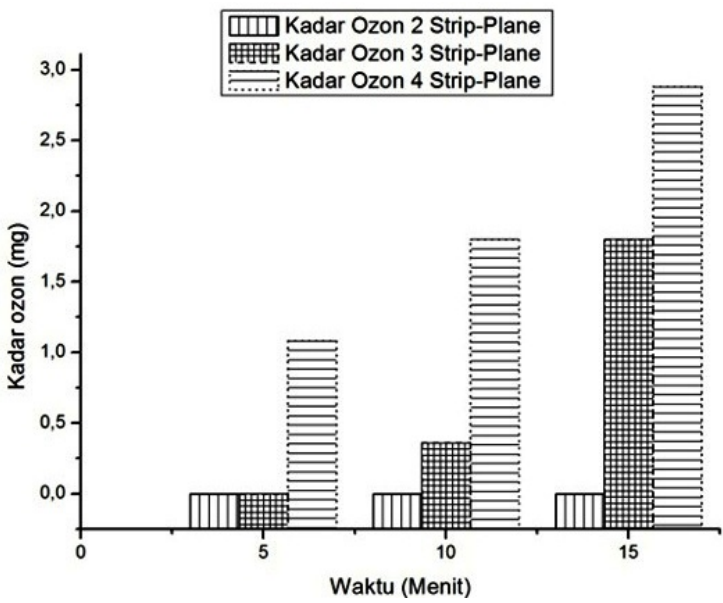

Gambar 3: Kadar ozon pada elektroda strip-bidang.

tidak terjadi lucutan elektron. Pada elektroda strip-bidang dilakukan beberapa variasi pada jumlah strip-nya. Elektroda tersebut Terdiri dari 3 elektroda dengan jumlah strip dua, tiga dan empat. Elektroda dengan jumlah strip lebih banyak tentunya memiliki bagian tepi yang lebih banyak daripada elektroda dengan jumlah strip lebih sedikit. Namun posisi kedua elektroda sangat mempengaruhi plasma yang terbentuk.

Elektroda strip-bidang dibuat dari dua lempeng tembaga dengan lempeng bagian pertama berupa tembaga persegi panjang kecil dan bagian kedua berupa persegi panjang besar. Variasi dilakukan pada jumlah elektroda persegi panjang kecil. Elektroda dipisahkan dengan jarak $1 \mathrm{~cm}$ yang dihubungkan dengan tegangan tinggi. Elektroda ditempatkan dalam balok kecil terbuat dari akrilik yang dilubangi kedua sisinya untuk jalan udara keluar dan masuk reaktor. Hasil pengukuran ozon pada model elektroda strip-bidang ditunjukkan pada Gambar 3.

Letak elektroda generator ozon mempengaruhi medan listrik yang terjadi. Semakin jauh jarak antara elektroda, maka semakin kecil medan listrik yang timbul [6]. Pada penelitian ini digunakan beberapa jenis elektroda untuk membuat generator ozon. Salah satunya adalah elektroda Stripbidang digunakan dalam penelitian ini seperti pada Gambar 1. Elektroda Strip-bidang dengan dielektrikum udara, cenderung terjadi spark pada bagian tepi, spark yang timbul bergerak antara elektroda Strip dan bagian lempengan tembaga sebagai plane. Daya masukkan kumparan primer
17,44 W sudah mampu menimbulkan spark dan lucutan elektron mampu bertumbukan dengan molekul gas dalam reaktor. Berdasarkan hasil eksperimen diketahui bahwa elektroda Strip-bidang menghasilkan ozon yang lebih tinggi ketika jumlah garisnya lebih banyak. Namun ada beberapa kendala pada pemasangan elektroda yang jarak antara kedua elektroda tidak bisa presisi $100 \%$.

Pengujian pada elektroda koaksial banyak terjadi spark terutama pada bagian pinggiran dari elektroda. Daya yang dibutuhkan juga sangat rendah, tetapi ozon yang terbentuk terlalu kecil seperti pada Gambar 2. Generator ozon dengan elektroda koaksial memiliki medan listrik yang besar pada

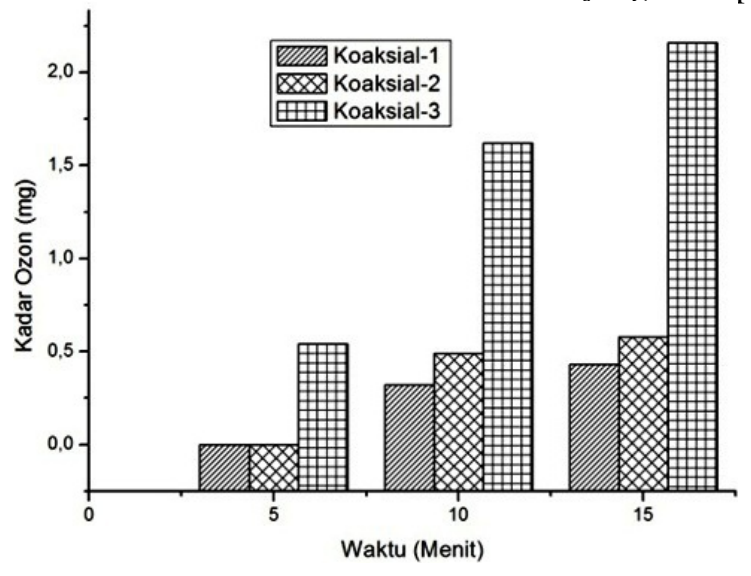

Gambar 4: Kadar ozon elektroda koaksial.

elektroda dalam karena luas penampang yang kecil [7]. Namun dengan kondisi interaksi elektroda yang tidak menggunakan dielektrikum menyebabkan arus lucutan mudah membesar dan timbul spark. Sehingga dibutuhkan jarak yang tepat antara dua elektroda.

\section{SIMPULAN}

Elektroda 4 strip bidang menghasilkan ozon terlarut 2,87 mg saat gas luaran dialirkan ke dalam larutan KI selama 15 menit. Pada elektroda koaksial dengan diameter $3 \mathrm{~cm}$ menghasilkan ozon 2,17 mg dalam waktu 15 menit tetapi dengan daya yang lebih kecil dari daya yang digunakan oleh elektroda strip bidang.
[1] M. Hijosa-Valsero, et al., J. Hazard. Mater., 262, 664-673 (2013).

[2] T.-L. Sung, et al., Vacuum, 90, 65-69 (2013).

[3] M. Facta, et al., Improvement in ozone generation with low voltage high frequency power converters, in Power and Energy Conference, 2008. PECon 2008. IEEE 2nd International, 2008, pp. 1446-1450.

[4] C. O'Donnell, et al., Ozone in Food Processing (1 edition. Chich- ester, West Sussex?; Ames, Iowa: Wiley-Blackwell, 2012).

[5] M. Dobrot, et al., APCBEE Procedia, 5, 33-37 (2013).

[6] A. K. Srivastava, and G. Prasad, J. Electrost., 72(2), 140-146 (2014).

[7] Q. Guo, et al., Catal. Today, 211, 156-161 (2013). 